\title{
Aromatic Compounds
}

National Cancer Institute

\section{Source}

National Cancer Institute. Aromatic Compounds. NCI Thesaurus. Code C1915.

Historically, the term "aromatic" originally referred to the smell of selected compounds that later were found to contain benzene or fused benzene rings in the structure. In a structural sense, it designates compounds that, in accordance with the theory of Huckel, have a cyclic, delocalized $(4 n+2)$ pi-electron system. This includes arenes and their substitution products (e.g., benzene, naphthalene, toluene). The term has been generalized to include aromatic heterocyclic structures, such as thiophene and pyridine, but it is more precise to call compounds of the latter type heteroaromatic. 